\title{
Water content of aged aerosol
}

\author{
G. J. Engelhart ${ }^{1}$, L. Hildebrandt ${ }^{1}$, E. Kostenidou ${ }^{2,4}$, N. Mihalopoulos ${ }^{3}$, N. M. Donahue ${ }^{1}$, and S. N. Pandis ${ }^{1,2,4}$ \\ ${ }^{1}$ Department of Chemical Engineering, Carnegie Mellon University, Pittsburgh, PA, USA \\ ${ }^{2}$ Department of Chemical Engineering, University of Patras, Patras, Greece \\ ${ }^{3}$ University of Crete, Environmental Chemical Processes Laboratory (ECPL), Heraklion, Greece \\ ${ }^{4}$ Institute of Chemical Engineering and High Temperature Chemical Processes (ICE-HT), Foundation of Research and \\ Technology (FORTH), Patras, Greece
}

Received: 25 August 2010 - Published in Atmos. Chem. Phys. Discuss.: 14 September 2010

Revised: 30 December 2010 - Accepted: 16 January 2011 - Published: 1 February 2011

\begin{abstract}
The composition and physical properties of aged atmospheric aerosol were characterized at a remote sampling site on the northern coast of Crete, Greece during the Finokalia Aerosol Measurement Experiment in May 2008 (FAME-2008). A reduced Dry-Ambient Aerosol Size Spectrometer (DAASS) was deployed to measure the aerosol water content and volumetric growth factor of fine particulate matter. The particles remained wet even at relative humidity (RH) as low as $20 \%$. The aerosol was acidic during most of the measurement campaign, which likely contributed to the water uptake at low RH. The water content observations were compared to the thermodynamic model E-AIM, neglecting any contribution of the organics to aerosol water content. There was good agreement between the water measurements and the model predictions. Adding the small amount of water associated with the organic aerosol based on monoterpene water absorption did not change the quality of the agreement. These results strongly suggest that the water uptake by aged organic aerosol is relatively small (a few percent of the total water for the conditions during FAME-08) and generally consistent with what has been observed in laboratory experiments. The water concentration measured by a Q-AMS was well correlated with the DAASS measurements and in good agreement with the predicted values for the $\mathrm{RH}$ of the QAMS inlet. This suggests that, at least for the conditions of the study, the Q-AMS can provide valuable information about the aerosol water concentrations if the sample is not dried.
\end{abstract}

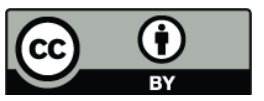

Correspondence to: S. N. Pandis (spyros@chemeng.upatras.gr)

\section{Introduction}

Water uptake by atmospheric particles affects their size, lifetime (Kreidenweis et al., 2001; Spichtinger and Cziczo, 2008), optical (Malm and Day, 2001; Sequeira and Lai, 1998) and chemical properties. This can influence their interaction with climate, their deposition inside the humid respiratory tract and corresponding health effects (Martonen and Zhang, 2003; Löndahl et al., 2008).

Atmospheric aerosol can exist in multiple thermodynamically stable and metastable states. For simple salt systems a dry particle will uptake water at a critical relative humidity $(\mathrm{RH})$, called the deliquescence point (DRH), grow suddenly, and then continue to grow as RH is increased further. On the return branch of decreasing $\mathrm{RH}$ the salt particle can exhibit a hysteresis behavior by not following the same path but retaining water past the DRH until it crystallizes and collapses to its dry size at a lower RH known as the efflorescence point (ERH). For simple inorganic salts the deliquescence and efflorescence points are well known (Tang, 1997; Seinfeld and Pandis, 2006). The behavior of complex mixtures including several organic components is not well understood, making it difficult to predict the liquid water concentrations of atmospheric particles. For RH less than $80 \%$ or so it is not clear if the ambient particles are liquid droplets or dry particles.

The hygroscopic tandem differential mobility analyzer (H-TDMA) is one tool often used to measure hygroscopic growth of ambient particles (Berg et al., 1998; Cocker et al., 2001; Nilsson et al., 2009). The H-TDMA size selects a nearly monodisperse stream of dried aerosol, exposes the size-selected particles to an elevated RH and then measures the resultant size distribution, and thus growth, with a scanning mobility particle sizer (SMPS). To facilitate intercomparisons among different studies most H-TDMA

Published by Copernicus Publications on behalf of the European Geosciences Union. 
measurements occur at $90 \% \mathrm{RH}$, limiting the ability to explore metastable states and deliquescence behaviors which would be observed at lower RH (Swietlicki et al., 2007). While other RHs can be selected this mode of H-TDMA operation requires additional sampling time and $\mathrm{RH}$ adjustments whereas the DAASS measures the particles at the constantly changing ambient RH automatically. The H-TDMA can be used to scan $\mathrm{RH}$ to reveal particle state information and it can provide valuable insights into the particle mixing state. For example, measurements at Jungfraujoch, which is a ground-based station representative of conditions in the free troposphere, were taken in the range of $10-85 \% \mathrm{RH}$ without evidence of efflorescence behavior (Weingartner et al., 2002; Sjogren et al., 2008). Choi and Chan (2002) have shown that organic components have the potential to delay or inhibit efflorescence, but a lack of efflorescence is also consistent with sulfate aerosols that are not fully neutralized (Martin, 2000; Khlystov et al., 2005).

H-TDMA studies have found evidence that several organic particulate matter (PM) components are hygroscopic and can absorb water (Dick et al., 2000) while others have shown that organics can impact the water uptake of the inorganic PM components both positively and negatively for non-urban and urban sampling locations, respectively (Saxena et al., 1995; Cruz and Pandis, 2000). Smog-chamber secondary organic aerosol measurements have found a hygroscopic growth factor $\left(D_{p, \text { wet }} / D_{p, \text { dry }}\right)$ of 1.1 at $85 \%$ RH (Virkkula et al., 1999).

Despite the many contributions of H-TDMA measurements, this technique cannot easily measure the liquid water content of atmospheric particles in their ambient state. This is because the particles are dried prior to sampling, and then re-wetted. Some species other than water may be removed during this drying process or the particles may effloresce or their morphology may change altering their physical characteristics. Scanning different particle sizes and $\mathrm{RH}$ values in the H-TDMA approach also requires significant time making the measurement in an environment where the aerosol composition changes continuously quite challenging. Other approaches have been used to estimate the liquid water content of ambient particles and sometimes to attempt to constrain the contribution of organic material to the liquid water content. Chemical analysis combined with filters weighed at varying $\mathrm{RH}$ have been used to determine the amount of water attributable to the inorganic constituents in filter samples from Research Triangle Park, North Carolina. The excess liquid water (about 20\%) was attributed to the organic compounds (Speer et al., 2003). Other researchers have used a nephelometer, comparing the scattering at ambient RH to the scattering at a reduced RH (Covert et al., 1979). This method was used in several national parks and found that particles retained water to very low RH at some locations (Great Smoky Mountains and Big Bend), whereas evidence of efflorescence was observed at the Grand Canyon (Malm et al, 2000; Malm and Day, 2001; Malm et al., 2003). This work also suggested that organic aerosols were weakly hygroscopic.
The Dry-Ambient Aerosol Size Spectrometer (DAASS) was developed to make direct in situ measurements of the water content of the entire distribution of ambient aerosols (Stanier et al., 2004). The DAASS was deployed for field monitoring during the Pittsburgh supersite, where a seasonal deliquescence behavior was observed as well as an increased water concentration (compared to the theoretically expected based on the inorganic PM) due to the organic component of the aerosol (Khlystov et al., 2005). The DAASS differs from the H-TDMA in that it measures the aerosol water concentration of the full $\mathrm{PM}_{0.5}, \mathrm{PM}_{1}$ or $\mathrm{PM}_{10}$ distribution and does not focus on the behavior of particles of a given size. This allows integral information of desired size cuts to be gathered with high time resolution, but relinquishes some of the detailed information provided from an H-TDMA such as the mixing state of the particles. Finally, the reduced DAASS requires only one DMA compared to the two needed by the H-TDMA. The H-TDMA and the DAASS are quite complimentary focusing on different aspects of the atmospheric particle hygroscopic behavior.

Despite the known importance of water uptake in ambient aerosol systems there is a relative dearth of water measurements, and our comprehension is hampered by complexities of unknown organics combined with inorganic systems. In this work a reduced DAASS system is deployed for monitoring remote ambient aerosols in the critical size range of 10 to $500 \mathrm{~nm}$ at ambient and low $(<25 \%) \mathrm{RH}$. Additionally, a QAMS is used to monitor undried atmospheric particles. The goal is to determine the state (liquid or solid), water content, and volume growth factors of the particles and compare the observations to existing models for inorganic components in order to increase our understanding of the impact of organics on the complex atmospheric mixtures.

\section{Experimental}

\subsection{Sampling site}

Measurements were taken at the Finokalia station $\left(35^{\circ} 24^{\prime} \mathrm{N}\right.$, $25^{\circ} 60^{\prime} \mathrm{E}$ ) on the northeast coast of the island of Crete. The sampling station is located at a $250 \mathrm{~m}$ elevation far from any major local anthropogenic sources; the closest urban center is Heraklion with an approximate population of 150000 , which is approximately $50 \mathrm{~km}$ to the west. The island's location in the Eastern Mediterranean makes it an ideal location for sampling a variety of air masses that have been transported to Crete, including marine, African and European outflows. Further details of the sampling site are reported elsewhere (Mihalopoulos et al., 1997; Kouvarakis et al., 2000; Sciare et al., 2003). 


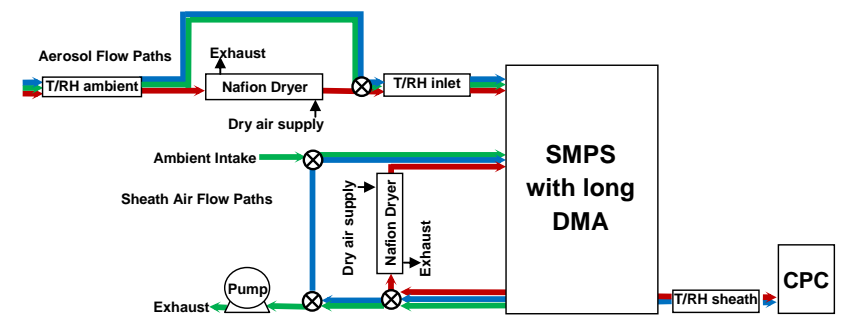

Fig. 1. Schematic of DAASS flow paths. Red is the dried sampling mode, blue is the ambient sampling mode and green is the vent mode. The internal SMPS pump for the sheath air recirculation is not shown explicitly in the schematic.

\subsection{Instrumentation}

The Finokalia Aerosol Measurement Experiment 2008 (Pikridas et al., 2010) took place from the beginning of May to beginning of June 2008 (FAME-08) and was part of the European Integrated Project on Aerosol Cloud Climate and Air Quality Interactions (EUCAARI) intensive campaign occurring throughout Europe during May 2008 (Kulmala et al., 2009). Specifically, FAME-08 investigated the physical, chemical and optical properties of aged European aerosol. The field mission's focus on a remote area complements other regional pollution measurements of the EUCAARI campaign. An overview of the FAME-08 field mission with details on each of the measurements described below has been presented by Pikridas et al. (2010). The present work focuses on measurements related to water uptake and our theoretical understanding of particulate water.

\subsubsection{Dry-Ambient Aerosol Size Spectrometer}

The DAASS consists of a scanning mobility particle sizer (SMPS, TSI 3936L), automated valves, and a particle conditioning system that measures aerosol number distributions at ambient RH and at low RH. A schematic is shown in Fig. 1. This is a reduced system based upon the design of Stanier et al. (2004). The SMPS is operated at a sheath to aerosol flow ratio of 5:1 lpm for a mobility diameter size range of particle measurements from approximately 10 to $500 \mathrm{~nm}$. Particles are equilibrated to a Boltzmann charge distribution with a ${ }^{85} \mathrm{Kr}$ neutralizer (TSI, $10 \mathrm{mCi} 3077 \mathrm{a}$ ). Each SMPS upscan is $5 \mathrm{~min}$ in duration followed by a 5 -minute downscan. The DAASS has two sampling modes, dried and ambient, and a vent mode (Fig. 1). The difference between the ambient and dry mode aerosol volume distributions is interpreted as the particulate water concentration.

In the dried sampling mode, the particles were passed through a modified inlet including a single-tube Nafion dryer in a stainless steel casing (Permapure MD-110, Toms River, $\mathrm{NJ})$. The sheath air line in the SMPS was also dried in a closed loop. Since the sheath line required a higher flow rate a multi-tube Nafion dryer (Permapure PD-50T) was used.
Dry air (Fig. 1) for the countercurrent streams of the Nafion dryers was provided at a rate of $5 \mathrm{lpm}$ for the inlet dryer and $15 \mathrm{lpm}$ for the sheath dryer by an oil-free compressor and a heatless dryer (not shown in Fig. 1; Permapure HD-2000) with final polishing via an activated carbon capsule (Whatman), silica gel dryer and a HEPA filter. The Nafion membrane selectively removes approximately $90 \%$ of the water vapor, while retaining the other compounds in the aerosol stream. Our laboratory tests did not show a loss of organics or nitrate from the aerosol sample due to the Nafion dryers.

In the ambient mode the Nafion dryers were bypassed using three-way solenoid valves (Alcon U33-42-21-12, Itasca, IL, USA). This operation was akin to a traditional SMPS measurement. After the ambient-mode scan ended the system was prepared for dry sampling in what is termed the dry preparation. This meant the automated valves entered the dry configuration, but size distribution data were not being collected to allow for system stabilization.

The third flow mode, a vent stage, rapidly prepared the system to switch from the dried sampling mode to the ambient sampling mode by operating in a once-through flow configuration (Fig. 1) in which dried air was exhausted and ambient air was drawn into the system. This air exchange was aided by a pump to drive a greater amount of air through the system without straining the SMPS blowers. One minute prior to the end of the vent mode the system was returned to a recirculating flow for the SMPS blowers to stabilize.

Maintaining the ambient temperature throughout the system was critical to sampling at ambient RH, so all of the instrumentation was placed outdoors. The DAASS system was shielded from sunlight by a large weatherproof canopy. In order to increase air flow around the system a fan was placed at the end of the canopy. Relative humidity and temperature were measured at three points in the DAASS (ambient at the entrance to DAASS, after the inlet dryer/bypass, and at the exit of the differential mobility analyzer column before the condensation particle counter (CPC, TSI 3772)). The RH data were logged by the LabView software, which also controlled the valves (Fig. 1).

As atmospheric particles lose water they shrink. However, the maximum mobility diameter measured by the SMPS is constant and determined by the sheath air flow rate and maximum voltage applied to the DMA column. As the aerosol is dried in the DAASS, additional particles enter the measurable sampling window. In order to determine the amount of water taken up by the particles we must apply a small correction for this sampling bias to exclude the additional particles in the dry distribution. Using the method of Stanier et al. (2004) the total measured volumes of the ambient and dry distributions are:

$$
V_{\mathrm{dry}}=\frac{\pi}{6} \int_{D_{\mathrm{d} 1}}^{D_{\mathrm{d} 2}} D^{3} n_{\mathrm{dry}}(D) d D
$$


$V_{\text {ambient }}=\frac{\pi}{6} \int_{D_{\mathrm{a} 1}}^{D_{\mathrm{a} 2}} D^{3} n_{\text {ambient }}(D) d D$

where $V_{\text {ambient }}$ is the total ambient particle volume concentration, $D$ is the particle mobility diameter, $D_{\mathrm{a} 1}$ and $D_{\mathrm{a} 2}$ are the upper and lower integration limits, respectively, of the ambient distributions, and $n(D)$ is the aerosol number distribution. To obtain $V_{\mathrm{dry}}$, the upper integration limit, $D_{\mathrm{d} 2}$, is adjusted so that the same number of particles are considered in both the ambient and dry distributions. This means that the upper integration limit for the dry distribution will be lower than that of the ambient distribution. While the lower integration limits, $D_{\mathrm{d} 1}$ and $D_{\mathrm{a} 1}$, will be impacted by the same distribution shift we will neglect this for two reasons. First, very few particles smaller than $15 \mathrm{~nm}$ were present during FAME-08 representing less than $1 \%$ of the total aerosol number concentration (Pikridas et al., 2010). Second, the smallest particles in the distribution contribute little volume (zero for all practical purposes during FAME-08) and therefore do not introduce significant error if neglected. We define the volume growth factor as:

$$
\mathrm{VGF}=\frac{V_{\mathrm{ambient}}}{V_{\mathrm{dry}}}=\frac{\int_{D_{\mathrm{a} 1}}^{D_{\mathrm{a} 2}} D^{3} n_{\mathrm{ambient}}(D) d D}{\int_{D_{\mathrm{d} 1}}^{D_{\mathrm{d} 2}} D^{3} n_{\mathrm{dry}}(D) d D}
$$

If we assume all the particles have the same growth factor by neglecting Kelvin effects and regarding the aged submicrometer particle population as homogeneous then:

$\mathrm{VGF}=\left(\frac{D_{\mathrm{a} 2}}{D_{\mathrm{d} 2}}\right)^{3}$

Iteration is used to find the size boundary, $D_{\mathrm{d} 2}$, which simultaneously satisfies Eqs. (3) and (4). The corresponding VGF then accounts for the differences between the ambient and dried distributions. Once the integration limit for the dry distribution has been determined the aerosol water concentration (for particles with diameter smaller than approximately $500 \mathrm{~nm}$ ) can be found by:

$m_{w}=\rho_{w}\left(V_{\text {ambient }}-V_{\text {dry }}\right)$

where $\rho_{w}$ is the density of water.

The internal mixture assumption is used to determine the upper limit of integration in the dried aerosol distribution $D_{\mathrm{d} 2}$ (Eqs. 1, 3 and 4). The sensitivity of the measured aerosol water concentration to this diameter has been explored by Stanier et al. (2004) in their paper describing the DAASS development and data analysis. These authors concluded that for an externally mixed population the growth factor in Eqs. (3) and (4) is approximately the volumeweighted average growth factor of the various externally mixed aerosol subpopulations. Simulations with log-normal externally mixed aerosol modes of different hygroscopicities showed that the growth factor calculated by Eqs. (3) and (4) may be biased low under this circumstance. This error was estimated to be small (a few percent at most) for the conditions of FAME-08 where the deviations from the internally mixed state (as indicated from the AMS size distributions) are small and the $D_{\mathrm{d} 2}$ diameter was close to the peak diameter of the accumulation mode (Hildebrandt et al., 2010).

The contribution of the sub- $100 \mathrm{~nm}$ particles to the aerosol volume and therefore the VGF was less than 5\% during the study and for the sub-50 nm it was much less than $1 \%$ (Pikridas et al., 2010). As a result the role of the Kelvin effect in the analysis of our measurements is negligible.

The effect of the water additivity assumption on the calculation of aerosol water concentration is easy to quantify through Eq. (5). Any deviation from ideality will introduce the same error in the water. For these aerosol systems where the aerosol water is determined mainly by the uptake of water by the sulfate salts the deviations are expected to be a few percent resulting in similar uncertainties. Finally, the maximum aerosol water at a $\mathrm{RH}$ of $10 \%$ is approximately $2 \%$ of the sulfate concentration. The average sulfate concentration during FAME-08 was $3 \mu \mathrm{g} \mathrm{m}^{-3}$, so the average effect of neglecting the water concentration of the dried PM during the DAASS operation should be less than $0.06 \mu \mathrm{g} \mathrm{m}^{-3}$. The uncertainty introduced by using a constant ammonium sulfate density is related to the difference between the ammonium sulfate and bisulfate densities ( 1.77 versus $1.78 \mathrm{~g} \mathrm{~cm}^{-3}$ ) so it is always much less than $1 \%$.

Stanier et al. (2004) have quantified the uncertainty of the DAASS water measurements and the factors affecting it. Particle losses for the size range examined here were determined to be less than $5 \%$. The same authors estimated an uncertainty of around $15 \%$ in VGF based on their measurements with model aerosols.

\subsubsection{Aerosol Mass Spectrometer}

A Quadrupole Aerosol Mass Spectrometer (Q-AMS, Aerodyne Research, Inc.) continuously measured the chemical composition of submicrometer non-refractory aerosol including sulfate, organics, nitrate, and ammonium. The QAMS operation alternated between sampling mass spectral information for mass to charge $(\mathrm{m} / \mathrm{z})$ ratios between 1 and 300 and sampling particle time of flight (pToF) aerodynamic size information every $15 \mathrm{~s}$. The Q-AMS was located in an air-conditioned room and particles were sampled through a $\mathrm{PM}_{10}$ sampling head positioned on the roof. The QAMS vaporizer was set at $600{ }^{\circ} \mathrm{C}$ to rapidly volatilize ammonium sulfate and any other non-refractory compounds that would quickly vaporize below $600^{\circ} \mathrm{C}$, as is typical for standard use of the instrument. Black carbon and other refractory compounds cannot be measured by this type of AMS. The measurements were analyzed with a standard batch and 
fragmentation table (Allan et al., 2004) with some minor modifications as described in Hildebrandt et al. (2010).

In this campaign the aerosol was sampled directly without drying of the sample. It has been shown that some particle water evaporates in the AMS aerodynamic lens (Murphy, 2007); consequently the AMS is not typically used for particle water measurements. Our objective is to establish a reliable protocol for using the AMS to measure particulate water. Determining the PM water with the Q-AMS requires careful adjustments to the standard Q-AMS fragmentation table to account for changes in absolute humidity. The challenge is to separate the gas-phase water signal from the total water signal at $m / z, 18$ so that the remaining water can be attributed to the particles. We make the assumption that the gas-phase ratio of $\mathrm{H}_{2} \mathrm{O}^{+} / \mathrm{N}_{2}^{+}$scales with absolute humidity. In the pToF spectra of the AMS, gas-phase species appear well before the particle-phase species; this can be used to separate the gas and particle-phase signals via integration of only the gas-phase signal. Due to inherent signal noise in the pToF distribution, the data was binned by absolute humidity and averaged before integration. For more details on this procedure, see Hildebrandt et al. (2010). A default relative ionization efficiency (RIE) for water of 1 was used as it is the default value for the AMS fragmentation table. Additionally, without further evidence to choose an alternate RIE, unity provides a convenient value for readers to calculate estimates using varied RIEs. Better estimates of the RIE of water are needed to fully constrain AMS measurements of particulate water as there are indications that the RIE of water is between 2 and 4. Mensah et al. (2010) have reported an RIE for water of 2, but this value is likely dependent upon the specific instrument and operating conditions.

\section{Results and discussion}

\subsection{Instrument performance}

Figure 2 shows a typical time series of $\mathrm{RH}$ throughout the DAASS flow configurations. The sheath RH is low during the dry sampling period. As the dry period ends, the valves switch to the vent mode where ambient air is rapidly drawn into the system causing a rapid increase in the $\mathrm{RH}$. The $\mathrm{RH}$ does not reach ambient conditions during the very rapid once-through vent flow, but quickly returns to near ambient $\mathrm{RH}$ when the valves switch to recirculating flow and allow the SMPS blowers and RH sensors to stabilize. After stabilization the ambient sample is measured for $5 \mathrm{~min}$ before the system enters the dry configuration. Here a rapid decrease in RH is observed. This is the "dry preparation" period during which size distribution data are not collected, but the system equilibrates to the low RH in preparation for the dry sampling period (which starts the repeating sequence). The instrument cycles through these flow modes collecting both ambient and dried particle distribution information.

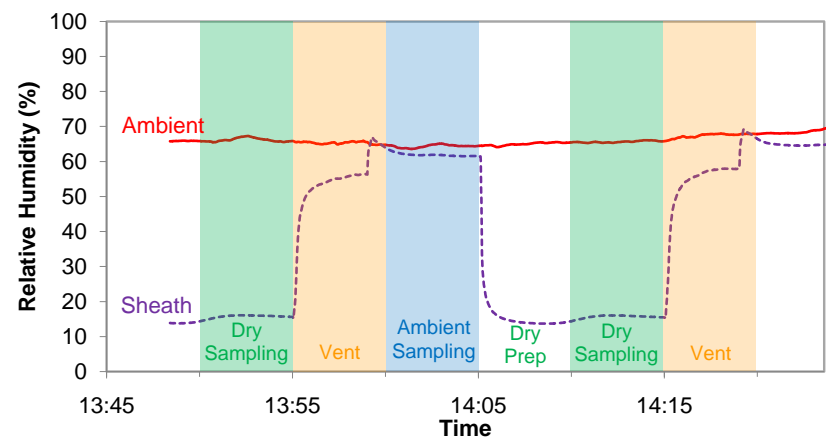

Fig. 2. Example of RH time series in DAASS for the various instrument modes.

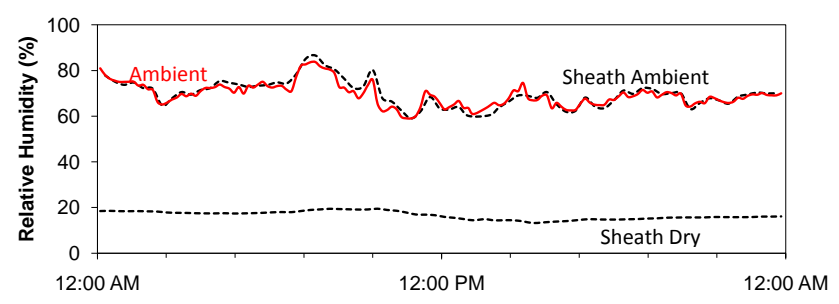

Fig. 3. Example data from midnight on 8 May to midnight on 9 May. Ambient RH (red) and sheath dry/ambient (black dashed).

During FAME-08 the sheath $\mathrm{RH}$ tracked the ambient $\mathrm{RH}$ fairly closely (Fig. 3). During the ambient sampling mode, the $\mathrm{RH}$ monitor located downstream of the inlet measured RH a few percent lower than ambient, potentially due to some heating from the solenoid valves. However, the particles rapidly equilibrated at the $\mathrm{RH}$ of the sheath air and this $\mathrm{RH}$ was used as the reference $\mathrm{RH}$ for the ambient measurement (Stanier et al., 2004). The dry relative humidity was lower than $25 \%$ even for the highest ambient RH conditions. The ambient RH during most of the study (approximately $90 \%$ of the time) was less than $70 \%$. During the short periods when the $\mathrm{RH}$ was high $(>70 \%)$ there were significant differences between the recorded $\mathrm{RH}$ values, so our analysis will focus on the data below $70 \%$ ambient $\mathrm{RH}$.

\subsection{DAASS water}

The particles during FAME-08 showed no signs of efflorescence (Fig. 4). The particles retained as much as $10 \%$ of their total particulate volume in water at $20 \% \mathrm{RH}$. At $50 \%$ $\mathrm{RH}$, where particulate matter mass is often measured in the European monitoring networks (Tsyro et al., 2005) the particles still contained approximately $40 \%$ water by volume. One potential explanation for the persistent liquid state of the particles is the acidity of the particles. Water retention has also been observed for acidic aerosols in Pittsburgh and Switzerland (Khlystov et al., 2005; Fisseha et al., 2006). Figure 5 shows the acidity ratio for submicrometer particles as calculated from AMS concentrations for the time periods of 


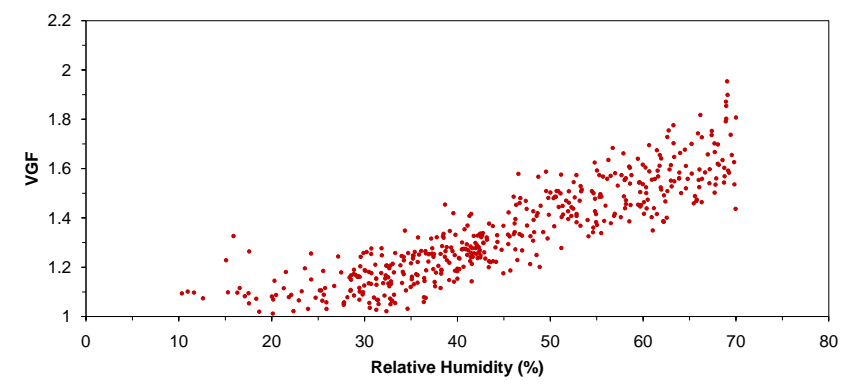

Fig. 4. Volume growth factor versus relative humidity for DAASS measurements with one hour averaging during FAME-08.

DAASS measurement. The acidity ratio is calculated according to:

Acidity Ratio $=\frac{\mathrm{mol}_{\mathrm{NH}_{4}^{+}}}{2 \cdot \mathrm{mol}_{\mathrm{SO}_{4}^{2-}}+\mathrm{mol}_{\mathrm{NO}_{3}^{-}}}$

where $\mathrm{mol}_{\mathrm{NH}_{4}^{+}}, \mathrm{mol}_{\mathrm{SO}_{4}^{2-}}$ and $\mathrm{mol}_{\mathrm{NO}_{3}^{-}}$are moles of ammonium, sulfate, and nitrate, respectively. Other species such as sodium chloride and dust were negligible in the size range of interest during FAME-08 (Pikridas et al., 2010). Acidity is not the only potential explanation, as deliquescence and efflorescence behavior has been shown to be inhibited for model aerosols by a number of organic components (Marcolli and Krieger, 2006).

The reduced DAASS measurements discussed here focused on particles much smaller than one micrometer (ambient dry sizes of less than $500 \mathrm{~nm}$ ) where the mass/volume contribution of sea-salt particles was very small even if the measurement site was close to the coast. Our focus was on the effect of aged organic aerosol on the hygroscopic behavior of the particles and we purposely tried to avoid the thermodynamic complications caused by the sea-salt.

The lack of efflorescence cannot be explained by measurement artifacts (e.g., due to long sampling times). Every 20 min a data point of VGF was collected. Due to the relative stability of the air masses this is a short enough time period to see efflorescence if it was persistent. Using the same setup Khlystov et al. (2005) did not have a problem observing efflorescence in different environments.

\subsection{Comparison to AMS Water}

Despite the potential loss of water from the particles in the aerodynamic lens of the AMS and the different $\mathrm{RH}$ values for the measurements, a strong correlation between measured DAASS water and measured AMS water was observed. Figure 6 shows the data binned by every $0.5 \mu \mathrm{g} \mathrm{m}^{-3}$ according to the DAASS water. The Q-AMS was located inside a room as opposed to the DAASS, which was located outside under ambient conditions. Ambient temperature averaged $19^{\circ} \mathrm{C}$ while the indoor temperature was on average $28^{\circ} \mathrm{C}$ over the

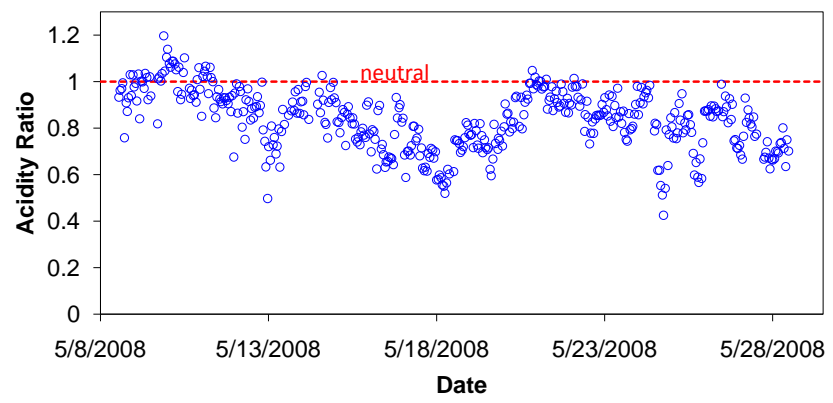

Fig. 5. Acidity ratio versus time as calculated from the molar ratio of ammonium over nitrate and sulfate as measured by the Q-AMS with one hour averaging.

period when both the Q-AMS and the DAASS were sampling. The sampling lines leading to the Q-AMS were sufficiently long for the sample to come into equilibrium with the room temperature, altering the $\mathrm{RH}$ from ambient conditions. The DAASS water measurements are at close to ambient RH while the AMS measurements are at "indoor" RH which was lower than the ambient during most of the study. $95 \%$ of the DAASS water measurements were below $5.5 \mu \mathrm{g} \mathrm{m}^{-3}$ and the highest two data points for DAASS water represent only $3 \mathrm{~h}$ over the entire campaign. The trend line is a weighted linear fit to the data and given by:

$($ AMS Water $)=0.44($ DAASS Water $)+0.74 \mu \mathrm{g} \mathrm{m}^{-3}$

The observed correlation $\left(R^{2}=0.90\right.$ for the water measurements below $8 \mu \mathrm{g} \mathrm{m}^{-3}$ ) was mainly due to the aerosol itself; for example during high sulfate periods both the DAASS and AMS measured high aerosol water concentrations. Of course, some of the correlation is due to the fact that both measurements correspond to the same absolute water vapor concentration. Other reasons contributing to the discrepancy include the slightly different size ranges measured by the two systems and the Q-AMS water measurement itself.

In an effort to compare the results of the two instruments for the campaign we averaged the DAASS and AMS water measurements for the same RH conditions using five RH bins. Even if these correspond to different time periods they were very well correlated $\left(R^{2}=0.95\right)$ :

$($ AMS Water $)=0.79($ DAASS Water $)-0.39 \mu \mathrm{g} \mathrm{m}^{-3}$

Use of the same average RH not only improves the correlation but also brought the slope close to unity and decreased the absolute value of the intercept. We will explore this rather surprising result regarding the water measured by the AMS in a subsequent section using thermodynamic theory and the Q-AMS inlet RH calculated from the ambient absolute humidity and indoor temperature. 


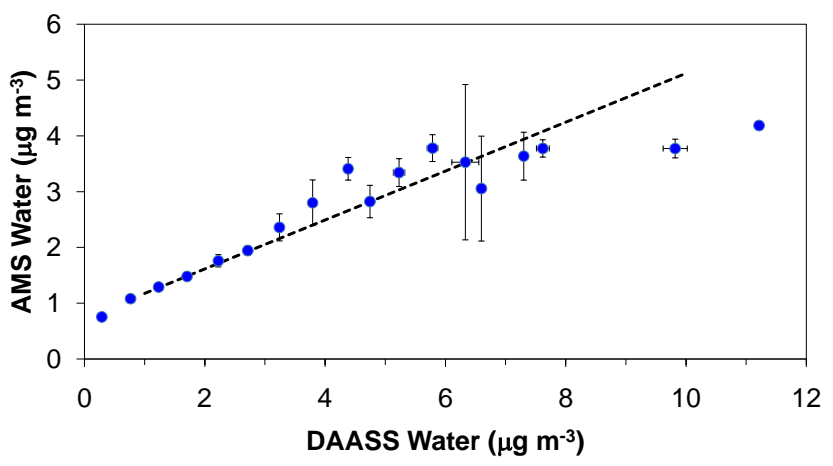

Fig. 6. DAASS water versus AMS water averaged for every $0.5 \mu \mathrm{g} \mathrm{m}^{-3}$ bin in the DAASS water. Error bars reflect one standard deviation divided by the square root of the total number of samples in that size bin minus one. The DAASS water was measured at ambient $\mathrm{RH}$ while the AMS water at the indoor $\mathrm{RH}$ ( $\mathrm{RH}$ of the sample at room temperature).

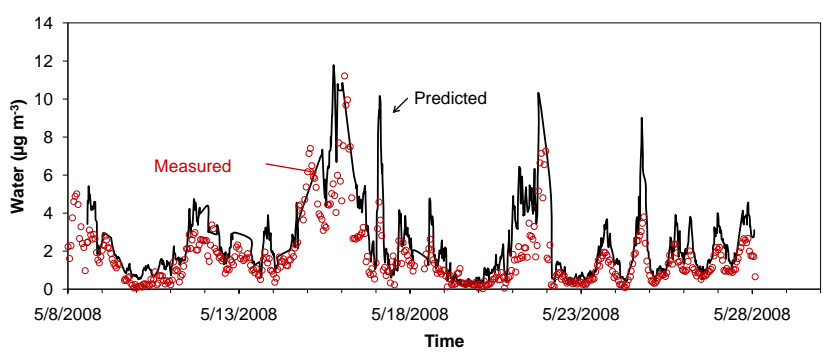

Fig. 7. Water versus time as calculated from E-AIM and measured by the DAASS at close to ambient RH. The water uptake by the organics is neglected in the predicted water concentration.

\subsection{Comparison to thermodynamic theory}

The inorganic concentrations for sulfate, ammonium, and nitrate measured by the Q-AMS were used as inputs into the Extended Aerosol Inorganic Model II (E-AIM, http://www. aim.env.uea.ac.uk/aim/aim.php; Carslaw et al., 1995; Clegg et al., 1998; Massucci et al., 1999) in conjunction with the DAASS sheath RH and the sheath temperature. The DAASS RH and temperature were averaged over the sampling interval of the Q-AMS. Production of all solids by the E-AIM model was suppressed and organic particulate related water was neglected. Similar calculations were conducted with EAIM Model III, which allows for additional inorganic components but restricts the temperature calculation to $298.15 \mathrm{~K}$. The resultant changes to aqueous water were negligible, so all calculations presented here employ Model II. The predicted VGF is calculated according to:

VGFPredicted $=\frac{\frac{\mathrm{m}_{\mathrm{SO}_{4}^{2-}}+\mathrm{m}_{\mathrm{H}^{+}}+\mathrm{m}_{\mathrm{NH}_{4}^{+}}}{\rho_{\left(\mathrm{NH}_{4}\right)_{2} \mathrm{SO}_{4}}}+\frac{\mathrm{m}_{\text {org }}}{\rho_{\text {org }}}+\frac{\mathrm{m}_{\mathrm{NO}_{3}^{-}}}{\rho_{\mathrm{NO}_{3}}}+\frac{\mathrm{m}_{\mathrm{H}_{2} \mathrm{O}_{\mathrm{aq}}}}{\rho_{\mathrm{H}_{2} \mathrm{O}}}}{\frac{\mathrm{m}_{\mathrm{SO}_{4}^{2-}}+\mathrm{m}_{\mathrm{H}^{+}}+\mathrm{m}_{\mathrm{NH}_{4}^{+}}}{\rho_{\left(\mathrm{NH}_{4}\right)_{2} \mathrm{SO}_{4}}}+\frac{\mathrm{m}_{\text {org }}}{\rho_{\mathrm{org}}}+\frac{\mathrm{m}_{\mathrm{NO}_{3}^{-}}}{\rho_{\mathrm{NO}_{3}}}+\frac{\mathrm{m}_{\text {lowRH, }} \mathrm{H}_{2} \mathrm{O}_{\mathrm{aq}}}{\rho_{\mathrm{H}_{2} \mathrm{O}}}}$

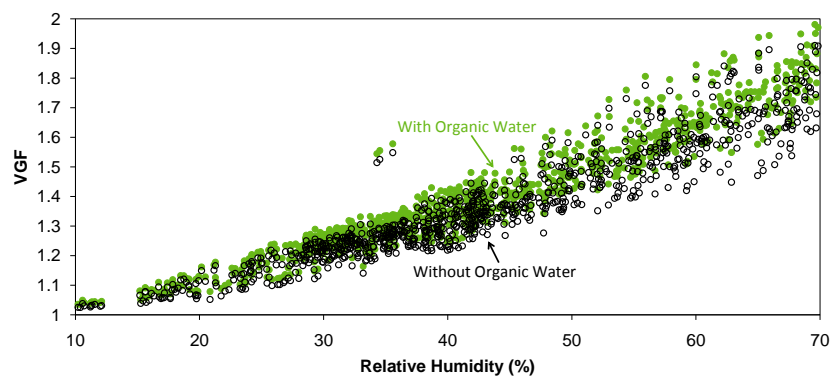

Fig. 8. Predicted volume growth factor versus $\mathrm{RH}$ predicted from the E-AIM model using only inorganics (black) and including water uptake from organics estimated from Koo et al. (2003) (green).

where $m_{i}$ and $\rho_{i}$ are the mass and density of the given species. The organic aerosol density during FAME-08 was determined to be approximately $1.35 \mu \mathrm{g} \mathrm{m}^{-3}$ by comparing the Q-AMS mass distribution to the SMPS size distribution measurements (Lee et al., 2010; Kostenidou et al., 2007). We use the ammonium sulfate density for both ammonium bisulfate and sulfate and also take advantage of the fact that there was very little nitrate during the study (Pikridas et al., 2010).

In order to compare the DAASS measurements to E-AIM theoretical calculations, Model II was used to simulate the low RH conditions of the sheath air to estimate the amount of water remaining during the low RH conditions. This correction was minor (around 6\%), but non-negligible. Particles were assumed to have negligible water below $10 \% \mathrm{RH}$.

The time series of the predicted and the measured aerosol water is shown in Fig. 7. The theory seems to reproduce the measurement time series well even if the water content of the organics is neglected in this calculation. Both the measurements and the predictions correspond to the DAASS measurement RH which differed by a few percent from the ambient RH (Fig. 2). If needed for other applications the model can be used for a first order correction of the measurements to the ambient RH.

The impact of organics on water uptake is still largely unknown. We use corrected UNIFAC predictions of water uptake from Koo et al. (2003) for $\alpha$-pinene oxidation products as a surrogate for our organic compounds. The concentration of organics was supplied from the Q-AMS. The estimated contribution of aerosol water associated with organics is small, especially compared with the contribution of water associated with inorganics at the same RH. The organic associated water has a small impact on the predicted VGF, a $3 \%$ average increase with the addition of water uptake by the organics, shown in Fig. 8. Therefore, the measured DAASS water is consistent with a relatively small water uptake of organics. The effect of organics on water uptake by aerosols in sub-saturated and super-saturated conditions can be quite different. The role of organics in the $\mathrm{CCN}$ concentrations in the same area is non-negligible (Bougiatioti et al., 2009). 


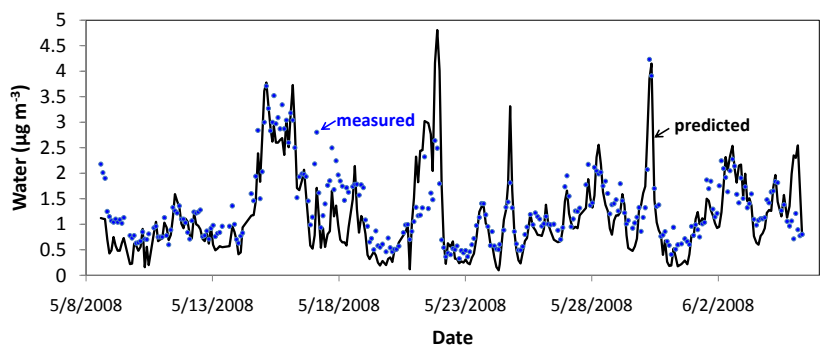

Fig. 9. Particulate water as measured by the AMS (blue points) versus predicted water (black line). The RH used for the model is the indoor $\mathrm{RH}$ ( $\mathrm{RH}$ of the aerosol sample at room temperature) at which the AMS measurements were performed.

We can use the same thermodynamic theory to determine the amount of water predicted under Q-AMS measurement conditions. Measurements of ambient temperature and RH are used to calculate the absolute humidity of the sample at the Q-AMS inlet. An indoor temperature measurement is then used to calculate the RH corresponding to the absolute humidity of the ambient sample. E-AIM is used to predict the particulate water content at these RH conditions using the same inorganic chemical composition information as before. The predictions are compared to the Q-AMS measurements of particulate water in Fig. 9. The agreement is very good. The predictions and measurements do not agree well on 21 May, which was an unusual day due to high concentrations of dust in the outflow from Africa. We disregard this day of measurements to find a correlation of:

$$
(\text { AMS Water })=0.77(\text { Predicted Water })+0.43 \mu \mathrm{g} \mathrm{m}^{-3}
$$

This correlation has an $R^{2}$ value of 0.73 . If we assume a zero intercept the correlation becomes:

$($ AMS Water $)=1.03($ Predicted Water $)$

This correlation has an $R^{2}$ value of 0.72 . However, as both the DAASS-AMS comparison shown in Fig. 6 and the E-AIM-AMS comparison shown in Fig. 9 show a small positive intercept in aerosol water measured by the Q-AMS, it is possible that the standard fragmentation table employed in this analysis slightly underestimates the water ion signal arising from fragmentation of either hydrated inorganic or oxygenated organic compounds.

Our Q-AMS analysis uses the standard batch table, which includes a RIE of water equal to 1 with respect to nitrate (Jimenez et al., 2003; Allen et al., 2004). The good agreement between the AMS water and the E-AIM prediction suggests that the product of the RIE of water and the evaporated fraction of the water in this system was close to unity during the study. Mensah et al. (2011) have recently reported a RIE of 2 for water in an AMS using crystal hydrates of ammonium oxalate, potassium oxalate and oxalic acid as well as sodium oxalate. If this RIE value is applicable to our study then our results suggest that approximately half of the water evaporated in our AMS and that this fraction was relatively constant during the measurement period. While the absolute aerosol concentration was quite variable during FAME08 (Hildebrandt et al., 2010; Pikridas et al., 2010) the shape of the volume/mass aerosol distribution was relatively stable (Pikridas et al., 2010). This stability of the aerosol volume distribution probably contributed to the surprising agreement of the AMS water measurement with the E-AIM predictions.

\section{Conclusions}

The aged aerosols sampled during the FAME-08 field mission on Crete were wet throughout the entire sampling period. This lack of efflorescence may be aided by the acidity of the particles that was common throughout the study. Additionally, our understanding of inorganic water uptake and organic water uptake reproduce the measurement data well. The E-AIM model for inorganics predictions is consistent with the DAASS measurements. Even when they are very aged, organics absorb a relatively small amount of particulate water, increasing total particulate water in this sulphur rich environment by only a few percent.

Interestingly, predictions of the particle water content for the measurement conditions of the Q-AMS agree with QAMS measurements quite well. This is a promising result for rapidly increasing our understanding of water in atmospheric particulate matter and should be considered in experimental design for future field missions. Combination of the DAASS and AMS systems in future studies in other environments may provide valuable information about our ability to monitor ambient particulate water. Clearly a lot of additional work is needed before the AMS can be used to measure particulate water routinely.

Acknowledgements. Special thanks to Claudia Mohr, Peter DeCarlo, Andre Prevot, and Urs Baltensperger for use and help with their Q-AMS and for helpful discussions of water measurements. We are grateful for three anonymous referees, the Paul Scherrer Institute group, J.-L. Jimenez and A. Middlebrook for their constructive comments which have been used to improve this paper. We acknowledge the United States National Science Foundation ATM-0732598 for funding.

Edited by: A. Wiedensohler

\section{References}

Allan, J. D., Delia, A. E., Coe, H., Bower, K. N., Alfarra, M. R., Jimenez, J. L., Middlebrook, A. M., Drewnick, F., Onasch, T. B., Canagaratna, M. R., Jayne, J. T., and Worsnop, D. R.: A generalised method for the extraction of chemically resolved mass spectra from Aerodyne aerosol mass spectrometer data, J. Aerosol Sci., 35, 909-922, doi:10.1016/j.jaerosci.2004.02.007, 2004. 
Berg, O. H., Swietlicki, E., and Krejci, R.: Hygroscopic growth of aerosol particles in the marine boundary layer over the Pacific and Southern Oceans during the First Aerosol Characterization Experiment (ACE 1), J. Geophys. Res., 103(D13), 16535, doi:10.1029/97JD02851, 1998.

Bougiatioti, A., Fountoukis, C., Kalivitis, N., Pandis, S. N., Nenes, A., and Mihalopoulos, N.: Cloud condensation nuclei measurements in the marine boundary layer of the eastern Mediterranean: $\mathrm{CCN}$ closure and droplet growth kinetics, Atmos. Chem. Phys., 9, 7053-7066, doi:10.5194/acp-9-7053-2009, 2009.

Carslaw, K. S., Clegg, S. L., and Brimblecombe, P.: A thermodynamic model of the system $\mathrm{HCl}-\mathrm{HNO}_{3}-\mathrm{H}_{2} \mathrm{SO}_{4}-\mathrm{H}_{2} \mathrm{O}$, including solubilities of $\mathrm{HBr}$, from $<200 \mathrm{~K}$ to $328 \mathrm{~K}$, J. Phys. Chem., 99, 11557-11574, 1995.

Choi, M. Y. and Chan, C. K.: The effects of organic species on the hygroscopic behaviors of inorganic aerosols, Environ. Sci. Technol., 36, 2422-2428, 2002.

Clegg, S., Brimblecombe, L., P. and Wexler, A. S.: A thermodynamic model of the system $\mathrm{H}^{+}-\mathrm{NH}_{4}^{+}-\mathrm{SO}_{4}^{2-}-\mathrm{NO}_{3}^{-}-\mathrm{H}_{2} \mathrm{O}$ at tropospheric temperatures. J. Phys. Chem. A102, 2137-2154, doi:10.1021/jp973043j, 1998.

Cocker, D. R., Whitlock, N. E., Flagan, R. C., and Seinfeld, J. H.: Hygroscopic properties of Pasadena, California aerosol, Aerosol. Sci. Tech. 35, 637-647, doi:10.1080/02786820120653, 2001.

Covert, D. S., Waggoner, A. P., Weiss, R. E., Ahlquist, N. C., Charlson, R. J.: Atmospheric aerosols, humidity and visibility, edited by: Hidy, G. M., Mueller, P. K., Grosjean, D., Appel, B. R., Weslowski, J. J., in: Character and Origins of Smog Aerosols. Wiley, New York, USA, 559-581, 1979.

Cruz, C. N. and Pandis, S. N.: Deliquescence and hygroscopic growth of mixed inorganic-organic atmospheric aerosol. Environ. Sci. Technol. 34, 4313-4319, 2000.

Dick, W. D., Saxena, P., and McMurry, P. H.: Estimation of water uptake by organic compounds in submicron aerosols measured during the Southeastern aerosol and visibility study, J. Geophys. Res., 105, 1471-1479, doi:10.1029/1999JD901001, 2000.

Fisseha, R., Dommen, J., Gaeggeler, K., Weingartner, E., Samburova, V., Kalberer, M., and Baltensperger, U.: Online gas and aerosol measurement of water soluble carboxylic acids in Zurich, J. Geophys. Res., 111, D12316, doi:10.1029/2005JD006782, 2006.

Hildebrandt, L., Engelhart, G.J., Mohr, C., Kostenidou, E., Bougiatioti, A., DeCarlo, P. F., Prevot, A. S. H., Baltensperger, U., Mihalopoulos, N., Donahue, N. M., and Pandis, S. N.: Aged organic aerosol in the Eastern Mediterranean: The Finokalia Aerosol Measurement Experiment - 2008, Atmos. Chem. Phys., 10, 4167-4186, doi:10.5194/acp-10-4167-2010, 2010.

Jimenez, J. L., Jayne, J. T., Shi, Q., Kolb C. E., Worsnop D. R., Yourshaw, I., Seinfeld, J. H., Flagan, R. C., Zhang, X., Smith K. A., Morris, J. W., and Davidotis, P.: Ambient aerosol sampling with an Aerosol Mass Spectrometer, J. Geophys. Res. 108, 8425, doi:10.1029/2001JD001213, 2003.

Khlystov, A., Stanier, C. O., Takahama, S., and Pandis, S. N.: Water content of ambient aerosol during the Pittsburgh Air Quality Study, J. Geophys. Res., 110, D07S10, doi:10.1029/2004JD004651, 2005.

Koo, B., Ansari, A. S., and Pandis, S. N.: Integrated approaches to modeling the organic and inorganic atmospheric aerosol components, Atmos. Environ., 37, 4757-4768, doi:10.1016/j.atmosenv.2003.08.016, 2003.

Kostenidou, E., Pathak, R. K., and Pandis, S. N.: An algorithm for the calculation of secondary organic aerosol density combining AMS and SMPS data, Aerosol Sci. Technol., 41, 1002-1010, doi:10.1080/02786820701666270, 2007.

Kouvarakis, G., Tsigaridis, K., Kanakidou, M., and Mihalopoulos, N.: Temporal variations of surface regional background ozone over Crete Island in the Southeast Mediterranean. J. Geophys. Res., 105, 399-407, doi:10.1029/1999JD900984, 2000.

Kreidenweis, S. M., Remer, L. A., Bruintjes, R., and Dubovik, O.: Smoke aerosol from biomass burning in Mexico: Hygroscopic smoke optical model, J. Geophys. Res., 106, 4831-4844, doi:10.1029/2000JD900488, 2001.

Kulmala, M., Asmi, A., Lappalainen, H. K., Carslaw, K. S., Pöschl, U., Baltensperger, U., Hov, Ø., Brenquier, J.-L., Pandis, S. N., Facchini, M. C., Hansson, H.-C., Wiedensohler, A., and O'Dowd, C. D.: Introduction: European Integrated Project on Aerosol Cloud Climate and Air Quality interactions (EUCAARI) - integrating aerosol research from nano to global scales, Atmos. Chem. Phys., 9, 2825-2841, doi:10.5194/acp-9-2825-2009, 2009.

Lee, B. H., Kostenidou, E., Hildebrandt, L., Riipinen, I., Engelhart, G. J., Mohr, C., DeCarlo, P. F., Mihalopoulos, N., Prevot, A. S. H., Baltensperger, U., and Pandis, S. N.: Measurement of the ambient organic aerosol volatility distribution: application during the Finokalia Aerosol Measurement Experiment (FAME2008), Atmos. Chem. Phys., 10, 12149-12160, doi:10.5194/acp10-12149-2010, 2010.

Löndahl, J., Pagelsb, J., Bomanc, C., Swietlickia, E., Masslinga, A., Risslerad, J., Blomberge, A., Bohgardb, M., and Sandstroumlme, T.: Deposition of biomass combustion aerosol particles in the human respiratory tract, Inhal. Toxicol., 40, 923-933, 10.1080/08958370802087124, 2008.

Malm, W. C. and Day, D. E.: Estimates of aerosol species scattering characteristics as a function of relative humidity, Atmospheric Environment 35, 2845-2860, doi:10.1016/S13522310(01)00077-2, 2001.

Malm, W. C., Day, D. E., and Kreidenweis, S. M.: Light scattering characteristics of aerosols as a function of relative humidity: Part I-a comparison of measured scattering and aerosol concentrations using the theoretical models, J. Air and Waste Manage. Assoc., 50, 686-700, 2000.

Malm, W. C., Day, D. E., Kreidenweis, S. M., Collett Jr., J. L., and Lee, T.: Humidity dependent optical properties of fine particles during the Big Bend regional aerosol and visibility study (BRAVO), J. Geophys. Res., 108, 4279, doi:10.1029/2002JD002998, 2003.

Marcolli, C. and Krieger, U. K.: Phase changes during hygroscopic cycles of mixed organic/inorganic model systems of tropospheric aerosols. J. Phys. Chem. A110, 1881-1893, doi:10.1021/jp0556759, 2006.

Martin, S. T.: Phase transitions of aqueous atmospheric particles, Chem. Rev., 100, 3403-3453, 2000.

Martonen, T. B. and Zhang, Z.: Deposition of sulfate acid aerosols in the developing human lung, Inhal. Toxicol., 5, 165-187, doi:10.3109/08958379309034500, 1993.

Massucci, M., Clegg, S. L., and Brimblecombe, P.: Equilibrium partial pressures, thermodynamic properties of aqueous and solid phases, and $\mathrm{Cl}_{2}$ production from aqueous $\mathrm{HCl}$ and 
$\mathrm{HNO}_{3}$ and their mixtures, J. Phys. Chem. A 103, 4209-4226, doi:10.1021/jp9847179, 1999.

Mensah, A. A., Buchholz, A., Mentel, Th. F., Tillmann, R., and Kiendler-Scharr, A.: Aerosol mass spectrometric measurements of stable crystal hydrates of oxalate and inferred relative ionization efficiency of water, J. Aerosol Science, 41, 11-19, doi:10.1016/j.jaerosci.2010.10.003, 2011.

Mihalopoulos, N., Stephanou, E., Kanakidou, M., Pilitsidis, S., and Bousquet, P.: Tropospheric aerosol ionic composition in the Eastern Mediterranean region, Tellus B-Chem. Phys. Meteorol., 49, 314-326, doi:10.1034/j.1600-0889.49.issue3.7.x, 1997.

Murphy, D.: The design of single particle laser mass spectrometers, Mass Spectrom. Rev., 26, 150-165, doi:10.1002/mas.20113, 2007.

Nilsson, E., Swietlicki, E., Sjogren, S., Löndahl, J., Nyman, M., and Svenningsson, B.: Development of an H-TDMA for longterm unattended measurement of the hygroscopic properties of atmospheric aerosol particles, Atmos. Meas. Tech., 2, 313-318, doi:10.5194/amt-2-313-2009, 2009.

Pikridas, M., Bougiatioti, K., Engelhart, G. J., Hildebrandt, L., Kostenidou, E., Mohr, C., Kouvarakis, G., Zarmpas, P., Psichoudaki, M., Gagne, S., Mihalopoulos, N., Pilinis, C., Hillamo, R., Baltensperger, U., Kulmala, M., and Pandis, S. N.: The Finokalia Aerosol Measurement Experiments - 2008 (FAME08): An Overview, Atmos. Chem. Phys., 10, 6793-6806, doi:10.5194/acp-10-6793-2010, 2010.

Saxena, P., Hildemann, L. M., McMurry, P. H., and Seinfeld, J. H.: Organics alter hygroscopic behavior of atmospheric particles, J. Geophys. Res., 100, 18755-18770, doi:10.1029/95JD01835, 1995.

Sciare, J., Bardouki, H., Moulin, C., and Mihalopoulos, N.: Aerosol sources and their contribution to the chemical composition of aerosols in the Eastern Mediterranean Sea during summertime, Atmos. Chem. Phys., 3, 291-302, doi:10.5194/acp-3-291-2003, 2003.

Seinfeld, J. H. and Pandis, S. N.: Atmospheric Chemistry and Physics - From Air Pollution to Climate Change (2nd Edition), John Wiley \& Sons, 450-460, 2006.

Sequeira, R. and Lai, K. H.: The effect of meteorological parameters and aerosol constituents on visibility in urban Hong Kong, Atmos. Environ., 32, 2865-2871, doi:10.1016/S13522310(97)00494-9, 1998.
Speer, R. E., Edney, E. O., and Kleindienst, T. E.: Impact of organic compounds on the concentrations of liquid water in ambient $\mathrm{PM}_{2.5}$, J. Aerosol Sci., 34, 63-77, 025002, doi:10.1016/S00218502(02)00152-0, 2003.

Spichtinger, P. and Cziczo, D. J.: Aerosol-cloud interactions - a challenge for measurements and modeling at the cutting edge of cloud-climate interactions, Environ. Res. Lett., 3, doi:10.1088/1748-9326/3/2/025002, 2008.

Stanier, C. O., Khlystov, A. Y., Chan, W. R., Mandiro, M., and Pandis, S. N.: A method for the in situ measurement of fine aerosol water content of ambient aerosols: The dry-ambient aerosol size spectrometer (DAASS), Aerosol Sci. Technol., 38, 215-228, doi:10.1080/02786820390229525, 2004.

Sjogren, S., Gysel, M., Weingartner, E., Alfarra, M. R., Duplissy, J., Cozic, J., Crosier, J., Coe, H., and Baltensperger, U.: Hygroscopicity of the submicrometer aerosol at the high-alpine site Jungfraujoch, $3580 \mathrm{~m}$ a.s.1., Switzerland, Atmos. Chem. Phys., 8, 5715-5729, doi:10.5194/acp-8-5715-2008, 2008.

Swietlicki, E., Hansson, H.-C., Hämeri, K., Massling, A., Petäjä, T., Tunved, P., Weingartner, E., Baltensperger, U., McMurry, P. H., McFiggans, G., Svenningsson, B., Rissler, J., Wiedensohler, A., and Kulmala, M.: Hygroscopic properties of sub-micrometer atmospheric aerosol particles measured with H-TDMA instruments in various environments - A review, Tellus B, 60, 353364, doi:10.1111/j.1600-0889.2008.00350.x, 2007.

Tang, I. N.: Thermodynamic and optical properties of mixedsalt aerosols of atmospheric importance, J. Geophys. Res., 102, 1883-1893, doi:10.1029/96JD03085, 1997.

Tsyro, S. G.: To what extent can aerosol water explain the discrepancy between model calculated and gravimetric $\mathrm{PM}_{10}$ and $\mathrm{PM}_{2.5}$ ?, Atmos. Chem. Phys., 5, 515-532, doi:10.5194/acp-5515-2005, 2005.

Virkkula, A., Van Dingenen, R., Raes, F., and Hjorth, J.: Hygroscopic properties of aerosol formed by oxidation of limonene, alpha-pinene, and beta-pinene, J. Geophys. Res., 104, 35693579, doi:10.1029/1998JD100017, 1999.

Weingartner, E., Gysel, M., and Baltensperger, U.: Hygroscopicity of aerosol particles at low temperatures. 1. New low-temperature HTDMA instrument: setup and first applications, Environ. Sci. Technol., 36, 55-62, doi:10.1021/es010054o, 2002. 